\title{
Granulocyte macrophage colony stimulating factor (GM-CSF) biological actions on human dermal fibroblasts
}

\author{
S. Montagnani, L. Postiglione1, G. Giordano-Lanza, F. Di Meglio, C. Castaldo, S. Sciorio, N.
} Montuori ${ }^{1}$, G. Di Spigna ${ }^{1}$, P. Ladogana 1 , A. Oriente ${ }^{2}$, and G. Rossi ${ }^{1}$

Dept. Scienze Biomorfologiche e Funzionali, ${ }^{1}$ Dept. Biologia e Patologia Molecolare e Cellulare, ${ }^{2}$ Dept. Medicina Clinica e Sperimentale, Facoltà di Medicina e Chirurgia, Università degli Studi "Federico II", via Pansini, 5, Naples, Italy

Key words: Granulocyte Macrophage-Colony Stimulating Factor (GM-CSF), Extra Cellular Matrix (ECM), human dermal fibroblasts

\section{SUMMARY}

Fibroblasts are involved in all pathologies characterized by increased ExtraCellularMatrix synthesis, from wound healing to fibrosis. Granulocyte Macrophage-Colony Stimulating Factor (GM-CSF) is a cytokine isolated as an hemopoietic growth factor but recently indicated as a differentiative agent on endothelial cells. In this work we demonstrated the expression of the receptor for GM-CSF (GMCSFR) on human normal skin fibroblasts from healthy subjects (NFPC) and on a human normal fibroblast cell line (NHDF) and we try to investigate the biological effects of this cytokine. Human normal fibroblasts were cultured with different doses of GM-CSF to study the effects of this factor on GMCSFR expression, on cell proliferation and adhesion structures. In addition we studied the production of some Extra-Cellular Matrix (ECM) components such as Fibronectin, Tenascin and Collagen I. The growth rate of fibroblasts from healthy donors (NFPC) is not augmented by GM-CSF stimulation in spite of increased expression of the GM-CSFR. On the contrary, the proliferation of normal human dermal fibroblasts (NHDF) cell line seems more influenced by high concentration of GM-CSF in the culture medium.

The adhesion structures and the ECM components appear variously influenced by GM-CSF treatment as compared to fibroblasts cultured in basal condition, but newly only NHDF cells are really induced to increase their synthesis activity. We suggest that the in vitro treatment with GM-CSF can shift human normal fibroblasts towards a more differentiated state, due or accompanied by an increased expression of GM-CSFR and that such "differentiation" is an important event induced by such cytokine.

\section{INTRODUCTION}

In the past few years a strict relation between the activity of some cytokines and the synthesis of some components of the Extra Cellular Matrix (ECM) has become evident. The pathway of such interaction are still incompletely known, but in the last few years the role of T lymphocytes through the action of several cytokines has been demonstrated 
(Fiocco et al., 1993), sometimes in relation to neuroendocrine pathways (Masi et al., 1999). In particular, IL-1 ( $\alpha$ and $\beta$ ), IL-2, IL-6 and TGF- $\beta$, biological mediators of inflammation and vascular alteration in rheumatic diseases (Cutolo, 1999) exert a stimulating action on fibroblast collagen synthesis. It is well known, for example, that the presence of fibronectin is increased in the deep dermis of patients suffering of some pathologies of connective tissue like Systemic Sclerosis (SSc) (Cooper et al., 1979) and is influenced by TGF- $\beta$ (Xu et al., 1991). On the other hand, changes in ECM structure and composition, as happens during morphogenesis, can have important regulatory effects on cell behavior (Sechler et al., 1998).

The Granulocyte Macrophage-Colony Stimulating Factor (GM-CSF) is a cytokine that induces the growth and the activation of monocytes and granulocytes. Stimulating effects on endothelium and connective tissue cells have also been demonstrated (Bussolino et al., 1991, Dedhar et al., 1988).

It is interesting to observe that the receptor for GMCSF is formed by two chains: the alpha chain is typical of the GM-CSF receptor (GM-CSFR) while the beta chain is common to the IL-3 and IL-5 receptors. In a previous work (Postiglione et al., 1998) we demonstrated by cytofluorimetry and immunofluorescence the expression of such a receptor on human normal fibroblasts from gingiva. We also showed its increase after stimulation with increasing doses of GM-CSF up to $100 \mathrm{ng} / \mathrm{ml}$. GM-CSF at the same doses was able to stimulate the proliferation of these fibroblasts in vitro.

It was known, on the other hand, that quiescent fibroblasts can produce GM-CSF when cultured in vitro (Kaushansky et al., 1998).

As fibroblasts are surely the most relevant cell population involved in the synthesis of collagenous and non-collagenous components of ECM, our purpose was now to investigate the biological significance of the expression of GM-CSFR by these cells. We have already described the relationship of GM-CSF treatment with the development of adhesion structures and cell proliferation in normal gingival fibroblasts (Postiglione et al., 1998).

This is particularly interesting for us, because we are involved in the study of Systemic Sclerosis (SSc) which is characterized by increased production of Collagen I and other Extra Cellular Matrix (ECM) components by fibroblasts. In addition, some years ago we demonstrated increased serum levels of GM-CSF in SSc patients (Riccio et al., 1996).

Recently, it has also been demonstrated that transgenic mice with enhanced expression of the gene for GM-CSF have high serum levels of this cytokine and develop fibrotic nodules inside skeletal muscles and diaphragm: these nodules contain macrophages and fibroblasts (Lang et al., 1997).

We hypothesize that some cytokines, markedly increased in some connective tissue diseases, may act as factors inducing the differentiation and the synthetic activity of cells instead of inducing proliferation.

In this work, we investigate the expression of the receptor for GM-CSF in human normal skin fibroblasts both from a stabilized cell line and from primary cultures obtained from healthy donors' skin biopsies. After having demonstrated the presence of GM-CSFR on cell membrane, we studied the effects of GM-CSF treatment in order to evaluate if this cytokine can modify fibroblast normal behaviour as regards GM-CSFR expression, cell growth and synthesis of Collagen I, Fibronectin and Tenascin.

In fact, even though there is a general agreement on the dramatic increase in Collagen (Kupper, 1995, Leroy, 1972), Fibronectin (Cooper et al., 1979) and Tenascin (Lacour et al., 1992) synthesis by fibroblast in connective tissue pathologies accompanied by an altered expression of integrins and adhesion molecules both in serum and on fibroblast surface (Bolberg et al., 1992, Gruschwitz et al.,1995), data on the fibroblasts activity under GM-CSF stimulation are still lacking.

\section{MATERIALS AND METHODS}

Surgical fragments from 5 volunteers ( 3 females and 2 males, $37 \pm 4$ years old) who underwent aesthetic surgery were used to obtain primary cultures of normal fibroblasts. We will indicate them as NFPC (Normal Fibroblasts Primary Cultures). Normal Human Dermal Fibroblasts (NHDF) cell line obtained from adult subjects without any transformation (McKeeham et Ham, 1977) was kindly gived by Alfonso Oriente, MD (Johns Hopkins University, Baltimore, USA).

For primary cultures, each biopsy fragment was mechanically dissociated under the stereo micro- 
scope and then submitted to trypsinization for 30 minutes at $37^{\circ} \mathrm{C}$. After repeated PBS washing, microfragments were plated and cultured as follows.

\section{Cell Culture}

Human normal fibroblasts from skin biopsies we named NFPC (Normal Fibroblasts Primary Cultures) and cell line cultures of human skin fibroblasts (NHDF) were cultured in Dulbecco's minimal essential medium (DMEM, BIOWhittaker, Belgium), containing $10 \%$ fetal calf serum (GIBCO, Grand Island, NY), 200mM L-glutamine, penicillin $(100 \mathrm{mg} / \mathrm{ml})$ and streptomycin $(100 \mathrm{mg} / \mathrm{ml})$. The plates were incubated at $37^{\circ} \mathrm{C}$, in the presence of $5 \% \mathrm{CO} 2$; the medium was replaced every 3 days. To facilitate immunofluorescence studies, sterile glass coverslips were put into some cell dishes before plating the fibroblasts, to allow cell attachment. We performed every experimental procedure four times, so as each result is the mean (+/-SD) value of four repeated experiments.

\section{Cell proliferation}

For cell number measurement, in every culture dish $2,5 \times 10^{5}$ cells were initially plated and grown in the same conditions, except for the addition of different doses of GM-CSF to the culture medium. After 24, 48 and 72 hours and after 9 days, cells were detached with EGTA $(10 \mathrm{mM}), \mathrm{pH} 7,4$, for 10 min at $+37^{\circ} \mathrm{C}$ and $50 \mathrm{~min}$ at $+4^{\circ} \mathrm{C}$, and counted in a Neubauer hemocytometer (Neubauer Manifacturing Co, Minneapolis, Minn.).

\section{Cytokine}

Human recombinant GM-CSF $(150 \mathrm{mg} / \mathrm{ml})$ was obtained from Schering Plough (County Cork, IR). Both cell line and normal skin fibroblast cultures were stimulated for 9 days with concentrations of GM-CSF ranging from 10 to $200 \mathrm{ng} / \mathrm{ml}$, according to previously evaluated optimal concentrations for GM-CSF receptor (GM-CSFR) modulation (Postiglione et al., 1998). Fresh factor was added every 3 days to the culture medium. Monoclonal antibody against GM-CSF (clone BVD2-23B6) from Pharmingen (S. Diego, California) was used to block GM-CSF effects on cultured cells. GMCSF effects were totally neutralized by incubation with $40 \mathrm{ng} / \mathrm{ml}$ rat anti-human GM-CSF monoclonal antibody for $40^{\prime}$ at $37^{\circ} \mathrm{C}$ and then added to the culture medium (Bussolino et al.,1991).

\section{Western Blotting}

NHDF cell line and NFPC from healthy donors were counted and $1 \times 10^{6}$ were grown in basal conditions and with 10, 100 or $200 \mathrm{ng} / \mathrm{ml} \mathrm{GM-CSF}$ for 6 days in $100 \mathrm{~mm}$ dishes. We used promonocytic cell line (U 937) as positive control for GM-CSFR expression. Cells were incubated for $10 \mathrm{~min}$ at $4^{\circ} \mathrm{C}$ with $0.5 \mathrm{ml}$ of lysis buffer (PBS, $1 \%$ Triton X-100) containing proteases inhibitors. Cell lysates were collected by scraping and centrifuged at 12,000 g for $5 \mathrm{~min}$ at $4^{\circ} \mathrm{C}$. The concentration of the protein in cell lysates was determined by a calorimetric assay (BioRad, Richmond, CO) and $100 \mu \mathrm{g}$ of total protein was incubated $5 \mathrm{~min}$ at $90^{\circ} \mathrm{C}$ in Laemmli sample buffer. Cell lysates were electrophoresed on $10 \%$ SDS-polyacrylamide gels. Gels were electroblotted and the membranes were blocked with $5 \%$ fat-free dry milk, $1 \%$ ovalbumin, $5 \%$ FCS and $7,5 \%$ glycine. After three washes with washing solution $(0,1 \%$ fat-free dry milk, $0,1 \%$ ovalbumin, $1 \%$ FCS in PBS), the membranes were incubated overnight at $4 \% \mathrm{C}$ with monoclonal anti-GMCSFR antibody at the concentration of $10 \mu \mathrm{g} / \mathrm{ml}$ in washing solution. After four washes, filters were incubated for $30 \mathrm{~min}$ at room temperature with horseradish peroxidase-conjugated goat antimouse antibody (BioRad) diluted 1:3000 in PBS. After three washes as above and three additional washes in TTBS (50 mM Tris pH 7,5, 0,5M NaCl, $0,2 \%$ Tween-20), the membranes were stained with an Enhanced Chemio Luminescence (ECL) system (Amersham, England).

\section{Enzyme-linked immunoassay (ELISA IN SITU)}

We measured ECM proteins production by Enzyme-linked immunoassay in situ. (Vitale et al., 1998). Cells unstimulated and cells treated with 10 and $100 \mathrm{ng} / \mathrm{ml}$ of GM-CSF were plated in multiwell plates and cultured until $96 \mathrm{~h}$. At appropriate times $(6,24,48,72,96 \mathrm{~h})$ they were fixed with methanol-acetone $(\mathrm{Vol} / \mathrm{Vol})$ for $10 \mathrm{~min}$ at room temperature and then air dried. They were blocked with PBS/BSA $0,5 \%$, for $2 \mathrm{hr}$ at $4^{\circ} \mathrm{C}$, and washed with Phosphate Buffered Saline (PBS) 1X. The wells were filled with $50 \mu \mathrm{l}$ antibodies (dilution 1:10) Goat collagen I, Rabbit anti-human fibronectin and tenascin (Chemicon, Temencula, CA), in PBS $/ 0,5 \%$ BSA and $0,2 \%$ Tween 20 and allowed to react for $1 \mathrm{hr}$ at room temperature.The 
disks were washed 3 times with PBS to remove non-reactive antibodies and filled with $50 \mu \mathrm{l}$ horseradish peroxidase-conjugated anti goat $\mathrm{IgG}$ for collagen I and anti-rabbit IgG for fibronectin and tenascin (Santa Cruz Biotechnology, Delaware Avenue Santa Cruz, CA) in 0,5\% BSA and 0,2\% Tween 20 PBS (dilution 1:1000) and allowed to react for $30 \mathrm{~min}$. Cells in multiwell plates were washed with PBS and filled with $500 \mu 11 \mathrm{mg} / \mathrm{ml}$ O-phenylenediamine, $0,006 \%$ hydrogen peroxide and $0,1 \mathrm{~mol} / \mathrm{L}$ citrate buffer $\mathrm{pH} 5, \mathrm{O}$. After $30 \mathrm{~min}$ incubation at $37^{\circ} \mathrm{C}$ in the dark, the reaction was stopped with $\mathrm{H}_{2} \mathrm{SO}_{4} 1 \mathrm{~N}$. The absorbance measurement was performed in a microplate reader (Diamedix BP96) at $450 \mathrm{~nm}$. Experiments were carried out and repeated three times. 96-well plates with studied cells filled with aspecific human IgG were used as negative controls and purified human collagen I, fibronectin and tenascin (Chemicon, Temencula, CA) were used as positive controls.

\section{Immunocytochemistry}

Glass coverslips with attached fibroblasts were fixed with 3\% formaldehyde in PBS for 3' at room temperature, gently washed with PBS and then incubated with rabbit anti-human antibodies against Fibronectin and $\alpha$-Actinin (Sigma, St. Louis, Missouri) or with mouse anti-human monoclonal antibodies against Vinculin, Paxillin, Talin, Tenascin, (Sigma) and GM-CSFR (IgM against $\alpha$ chain of GM-CSF receptor, clone M5D12 from Pharmingen) for 1 hour at $37^{\circ} \mathrm{C}$ in a humid chamber. All primary antibodies were diluted in PBS according to the manufacturers. After further washings with PBS, cells were stained with fluorescein or rhodamine labeled rabbit anti-mouse $\mathrm{IgG}$ in the case of monoclonal antibodies (IgM for anti-GM-CSFR) or goat anti-rabbit IgG (for polyclonal antibodies). Both steps required 1 hour incubation at room temperature, in a humid chamber. For actin visualization, cells on glass coverslips were fixed as above, permeabilized with Triton X100 buffer (20 mM HEPES, $300 \mathrm{mM}$ sucrose, $50 \mathrm{mM} \mathrm{NaCl}, 3 \mathrm{mM} \mathrm{MgCI} 2,0,5 \%$ Triton $\mathrm{X} 100, \mathrm{pH} 7,4)$ for 2' at room temperature and then stained with 1:40 PBS diluted fluorescein-labeled Phalloidin (FPHD, Sigma) for 1 hour at $37^{\circ} \mathrm{C}$ in a humid chamber. To show phosphotyrosine activity in adhesion plaques, permeabilized cells were stained with rhodamine-conjugated anti-phospho- tyrosine monoclonal antibody (Sigma). Double immunostaining was performed utilizing monoclonal and polyclonal antibodies (for example, anti-Fibronectin and anti-Tenascin) or Phalloidine staining and one antibody contemporarily.

Negative and positive controls were carried out as usual. Coverslips were then mounted with Moviol (Du Pont R.J. \& Co, Nemours, France) and observed with an Axiophot microscope (Leitz, Germany) equipped for epifluorescence and microphotography. Every sample was evaluated by three independent observers, using a four point arbitrary scale ranging from 0 to 3 .

\section{Statistical analysis}

We used the t-Student test for unpaired data for statistical evaluation of our data on cell proliferation, GM-CSF receptor expression (this was evaluated as Optical Density) and ELISA IN SITU data; a probability value of $\mathrm{p} \leq 0,05$ was accepted as statistically significant.

\section{RESULTS}

\section{Immunocytochemistry of GM-CSFR mem- brane expression}

Both NFPC and NHDF cells show a slight immunopositivity for GM-CSFR in basal conditions. The expression of GM-CSFR is enhanced on the membrane of fibroblasts under GM-CSF treatment in both types of cells. (Fig. 1).

\section{Western blot of cell lysates}

In order to identify the GM-CSF receptor $\alpha$ chain (GM-CSFR $\alpha$ ), whole cell lysates from NFPC and NHDF were subjected to Western blot with monoclonal anti-GM-CSF receptor $\alpha$-chain antibodies (Fig. 2). As expected, the receptor migrated in a band with an apparent molecular weight of $84 \mathrm{Kda}$. This band was present in all dermal fibroblasts lysates both from NHDF cell line both from NFPC primary cultures.

The GM-CSFR band has only slight intensity in NHDF, when compared with the U937 macrophage cell line we used as control, but is more evident in NFPC cells (Fig. 2). The expression of GM-CSFR is however always increased under treatment with the cytokine in all fibroblasts, and it is particularly enhanced in NFPC up to $200 \mathrm{ng} / \mathrm{ml}$ of GM-CSF (Fig. 3). 

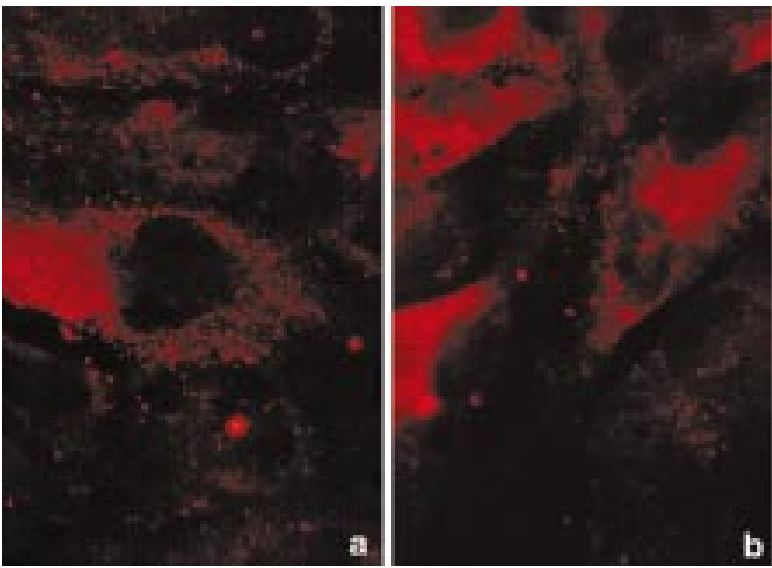

Fig. 1 - Immunopositivity for GM-CSFR on NHDF in basa conditions (a) and after 7 days stimulation with $100 \mathrm{ng} / \mathrm{ml}$ GM-CSF(b). Magnification 1060x

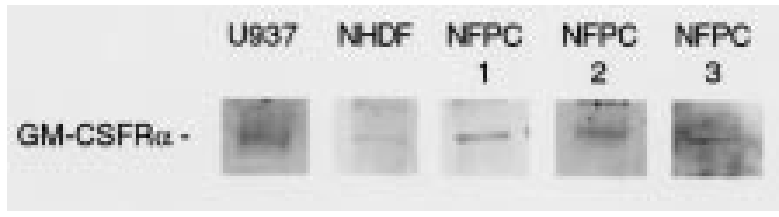

Fig. 2 - Western blot analysis of GM-CSFR alpha-chain in control (U937), in human skin fibroblast cell line (NHDF) and in 3 different healthy donors skin fibroblasts (NFPC 1,2 and 3).

A quantitative analysis of the GM-CSFR bands, obtained in a series of experiments similar to that shown in Fig. 2 and 3, is shown in Fig. 4.

\section{Cell proliferation}

NHDF and NFPC cells showed the proliferation rates reported in Fig. 5. The growth rate of NFPC does not appear significantly influenced by various GM-CSF doses, while NHDF cell line proliferation

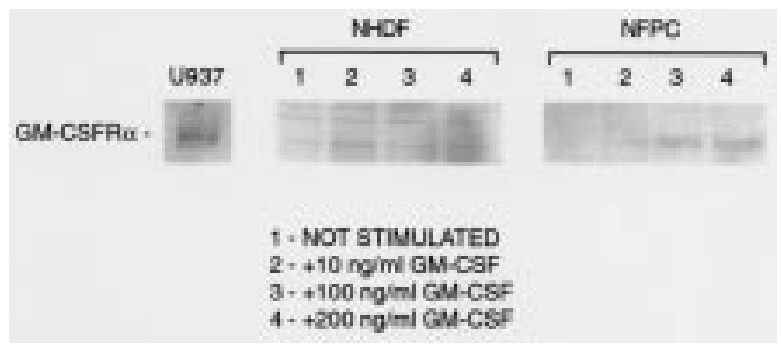

Fig. 3 - Western blot analysis of GM-CSFR alpha-chain expression in NHDF and NFPC after 7 days stimulation with different doses of human recombinant GM-CSF. U937 cells are used as control. The upper band in NHDF lanes 1, 2, 3, 4 is explained as background often observed also in nonimmune serum (data not shown). increase is evident and seems related to the higher dose of the cytokine. In fact, the proliferation rate is dramatically increased for these cells after nine days of culture but only at $80 \mathrm{ng} / \mathrm{ml}$ of GM-CSF.

\section{Cell adhesion}

As expected, all fibroblasts exhibited the common adhesion structures, with strong immunopositivity for Vinculin, $\alpha$-Actinin, Paxillin and an early, strong Phosphotyrosine-related activity in basal condition. On the other hand, adhesion structure components are more expressed under GM-CSF treatment at low doses (Fig. 6). Immunopositivity for adhesion markers like Vinculin, Talin, $\alpha$-Actinin and Paxillin is very strong and widely distributed on the cell surface which adheres to glass coverslips in the culture dishes, with abundant and well-structured adhesion plaques and dot-like structures immunopositive for Vinculin and alpha-actinin. At high GM-CSF doses, such structures are always less evident.

\section{Extra-Cellular Matrix synthesis}

Both immunocytochemistry and ELISA IN SITU data confirm, of course, that NFPC as well as NHDF cells are able to produce ECM components like Fibronectin, Tenascin and Collagen type I in vitro. The effects of stimulation with different doses of GM-CSF were studied with both methods to obtain a quantitative confirmation of the morphological observations which are summarized in Table 1. At the used doses of GM-CSF it was impossible to assess by immunofluorescence only a doseresponse relation; however, all these structures appeared well expressed (Fig. 7). On the other hand, ELISA IN SITU showed that the synthesis of these three ECM components is different if we compare NHDF line to NFPC from biopsies.

As regards Fibronectin, its production is perhaps more early in primary cultures than in fibroblast cell line, but GM-CSF is not able to induce any statistically significant increase in production from either culture (Fig. 8a).

As regards Tenascin, this protein is more rapidly produced by NHDF than by NFPC, but only NFPC primary cultures seem slightly sensitive to the effects of GM-CSF showing increasing synthesis of ECM (Fig. 8b).

The results of the study on Collagen type I synthesis are very different from the other ECM components we examined. It is noteworthy that here 


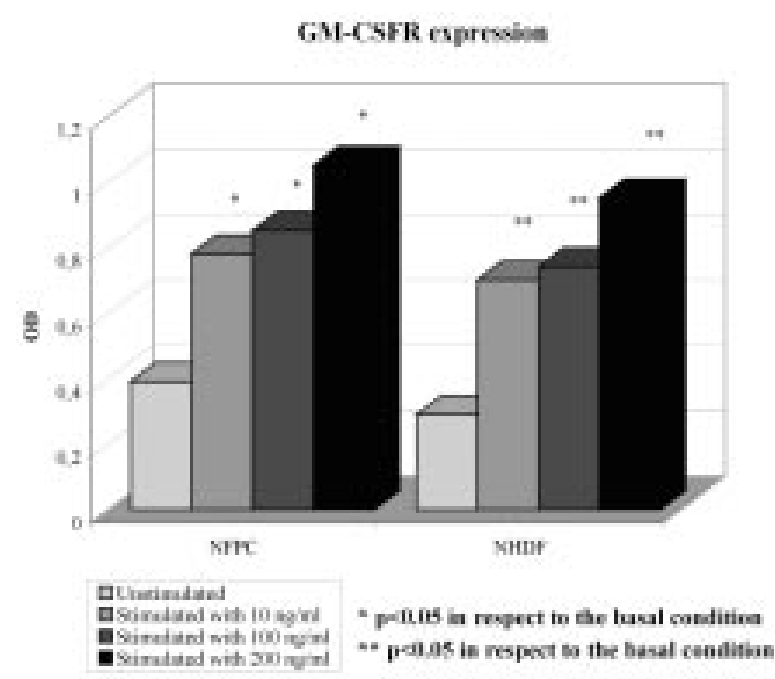

Fig. 4 - Quantitative analysis of GM-CSFR evidentiated by Western blot is expressed as Optical Density.
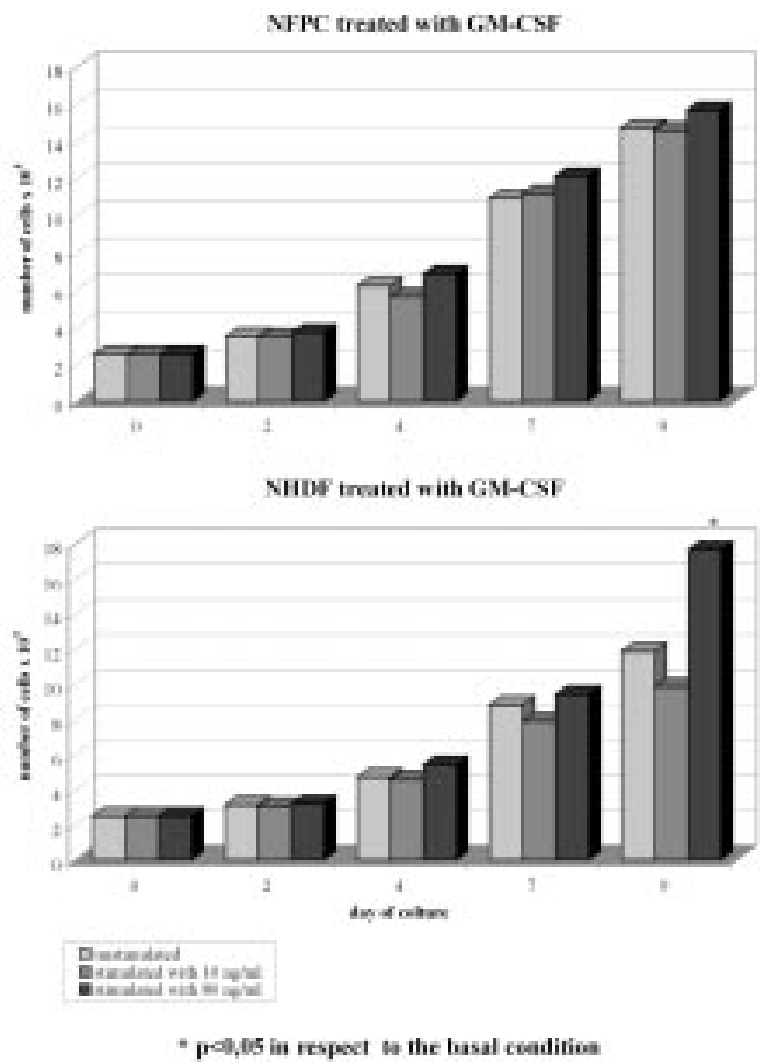

Fig. 5 - Cell proliferation rate of human normal skin fibroblasts from primary cultures (NFPC) and from cell line (NHDF) under stimulation with different doses of GM-CSF. It is evident a significant increase in growth rate for NHDF cell line under high dose of cytokine, while the effects of GM-CSF on NFPC cells are not important.
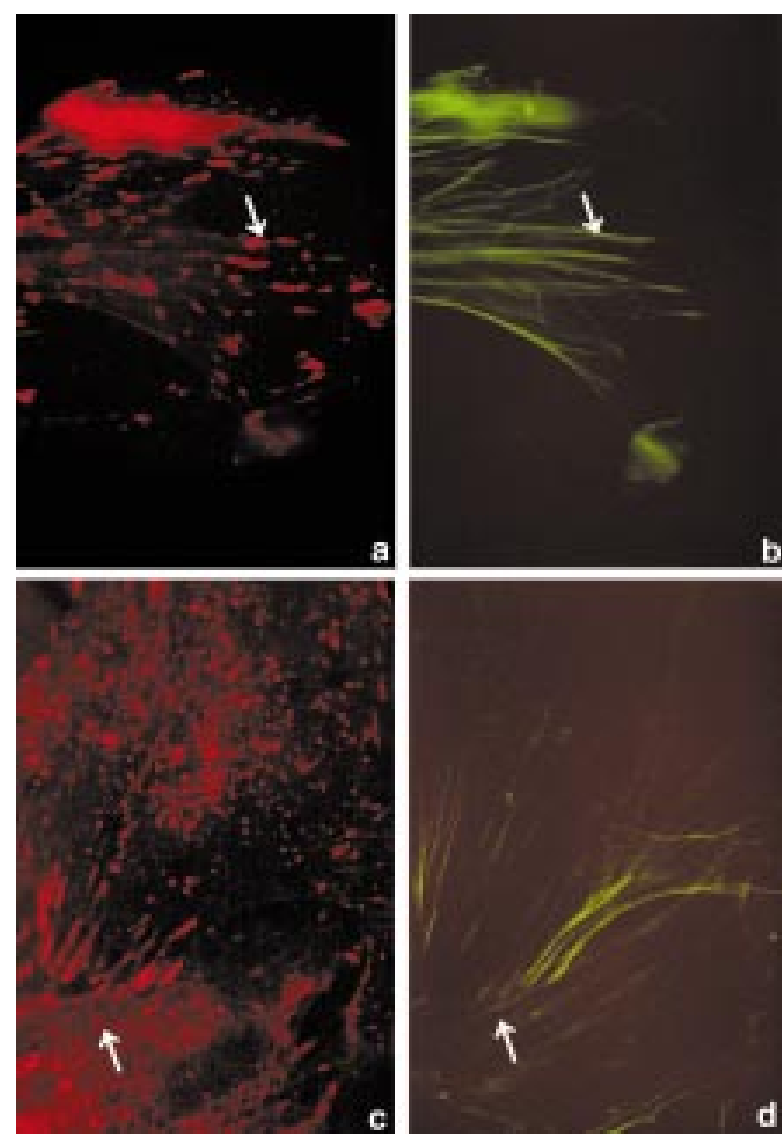

Fig. 6 - All adhesion structure components of both kind of cells are more expressed after 7 days GM-CSF treatment at low doses: a, red-stained Vinculin distribution in NFPC in basal condition; c, after treatment with $10 \mathrm{ng} / \mathrm{ml}$ GM-CSF. It is evident the increased number of plaques (arrow) and the unusual presence of "dots" (asterisk). In b and d, fluoresceine labeled Phalloidin individuate actin fibers in the same preparations. Magnification 1060x

the difference in the Collagen production between NFPC and NHDF line is near $50 \%$ and this gap is mantained after eight-days treatment with GMCSF (Fig. 8c), but in this case GM-CSF seems able to induce an increase only in NHDF type I Collagen synthesis activity (Fig. 9).

\section{DISCUSSION}

At first we demonstrated the expression of the receptor for GM-CSF on both fibroblast types we used and its relation with the concentration of the cytokine in the culture medium. This is important because GM-CSF, as other cytokines, is variously 
Table I

Immunopositivity of ECM components in basal conditions and after 7 days of GM-CSF stimulation

\begin{tabular}{lrrrrrr}
\hline ECM Components & \multicolumn{2}{c}{ Not stimulated } & \multicolumn{2}{c}{ GM-CSF 10 ng/ml } & \multicolumn{2}{c}{ GM-CSF 80 ng/ml } \\
& NFPC & NHDF & NFPC & NHDF & NFPC & NHDF \\
\hline Fibronectin & ++ & ++ & + & ++ & ++ & ++ \\
Tenascin & ++ & +++ & ++ & ++ & +++ & +++ \\
Collagen I & ++ & + & ++ & ++ & ++ & +++ \\
\hline
\end{tabular}

As regards the intensity of immunofluorescence, every sample was evaluated by three independent observers, using a four point arbitrary scale ranging from 0 to 3 .
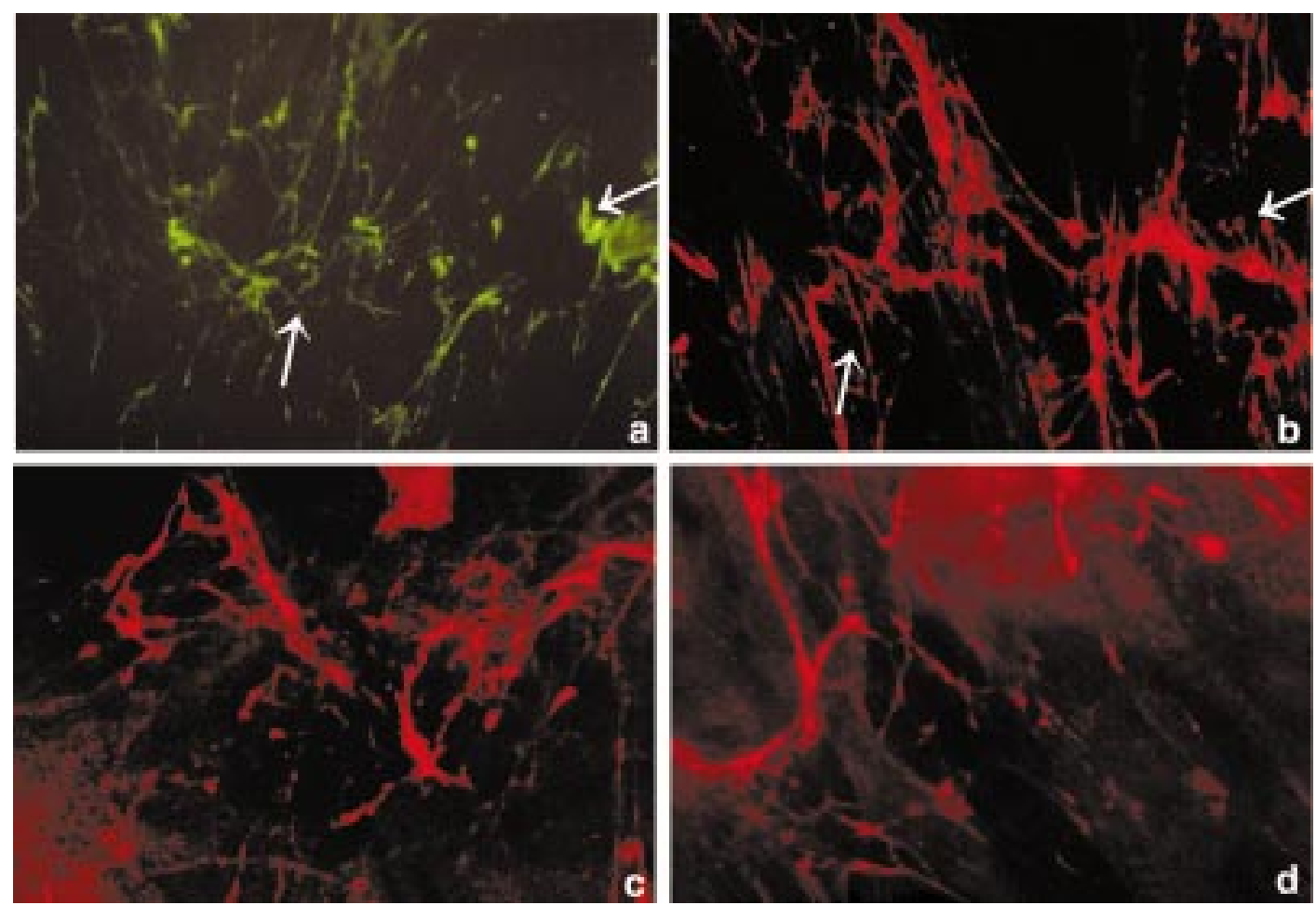

Fig. 7 - In basal conditions, Fibronectin (a) and Tenascin (b) appear well expressed and partially co-distributed using double immunostaining in NFPC cells (arrows). As regards Type I Collagen, it is more produced by NFPC cells (c) than by NHDF cell line (d). Magnification 1060x

produced in vivo during wound healing, inflammation and other pathologies. The increase of the expression of GM-CSFR related to increased concentration of GM-CSF in the culture medium prompted us to investigate the influence of GM-CSF on proliferation rate and biosynthetic activity of fibroblasts. In fact, data on fibroblast synthetic activity under GM-CSF stimulation are still lacking.
Extra-Cellular Matrix deposition and adhesion structures were generally more evident in cells obtained from skin biopsies, also after GM-CSF treatment, than in normal cutaneous fibroblasts from cell line cultures.

On the other hand, both kinds of human dermal fibroblasts exhibit a strongly adhesive phenotype and this finding could explain their poor growth 


\section{ExtraCellular Matrix production} under stimulation with GM-CSF

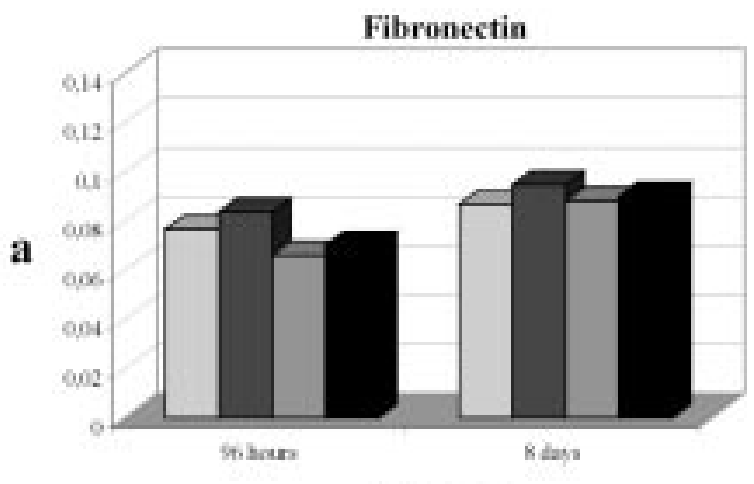

Tenascin

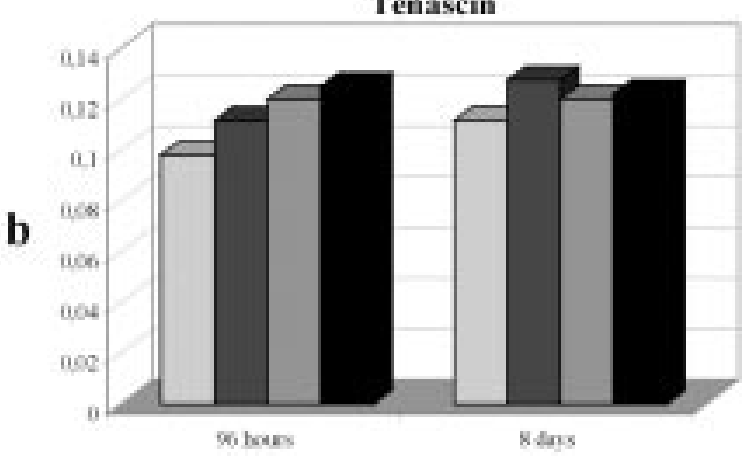

Collagen Type I

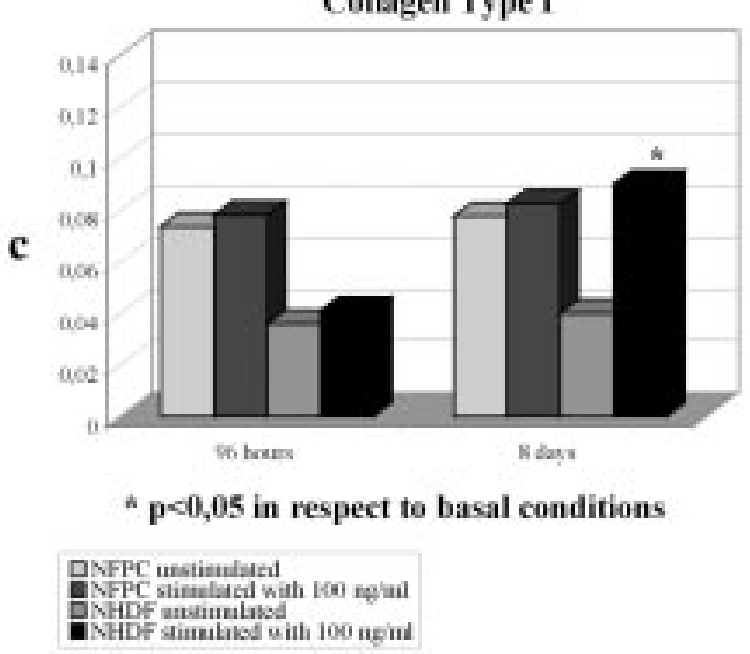

Fig. 8 - ELISA IN SITU evidentiates only slight modification in Fibronectin (a) and Tenascin (b) production both for NHDF and NFPC under stimulation with GM-CSF. The synthesis of Collagen type I by NHDF cells (c) is significantly increased by GM-CSF addition to the culture medium.

rates. The different synthetic activity among the two cell population we used is particularly evident when we point our attention to type I Collagen production: the NHDF line produces half the quantity of Collagen in respect of primary cultures but GM-CSF is really able to induce an increase of this synthetic activity.

In this regard, the effect of GM-CSF on this fibroblast cell line is surprising because it seems able to increase both the proliferation rate and the type I Collagen synthesis. It suggests the possibility that this molecule exerts its biological effect both on cell proliferation and differentiation.

We hypothesize that these fibroblasts undergo a shift toward a more differentiated state, due to or accompanied by an increased expression of GMCSFR, but such that this condition does not block their growth

It is interesting that in some epithelial cells the expression of an adhesive phenotype stimulates cell proliferation (Vitale et al. 1997). The NHDF cell line could exhibit a similar behavior.

It is therefore clear that the relationship between cell adhesion and proliferation is a complex one, depending on the cell type and the effect of several factors. Our data strongly suggest that GM-CSF is indeed one of the relevant cytokines, because it seems to induce a "less adhesive" phenotype at high concentration and this condition is probably related to the observed increase in proliferation.

In conclusion we think that the expression of GM-CSFR on cutaneous fibroblasts can play an important role, sometimes by influencing ECM deposition in addition to cell proliferation. The evidence that NHDF fibroblast cell lines from human normal skin after GM-CSF treatment have at the same time an enhanced expression of GMCSFR (associated with a mean increased proliferation index) and a stronger synthetic activity suggests that both aspects may be involved in the regulation of biosynthetic activity of these cells.

The effects of GM-CSF on the differentiation of fibroblasts, mediated by the increased expression of GM-CSF receptor, are probably amplified by the interaction with the ECM. It has in fact been demonstrated that ECM can bind GM-CSF and present it in a biologically active form (Roberts et al., 1988). It is also possible that fibroblasts play the double role of cells expressing the receptor for GM-CSF and also producing themselves the ligand, like many other cells involved in autocrine mechanisms. We hope our future investigation can someway clarify the relation of GM-CSF with some connective tissue diseases which are characterized by an early 

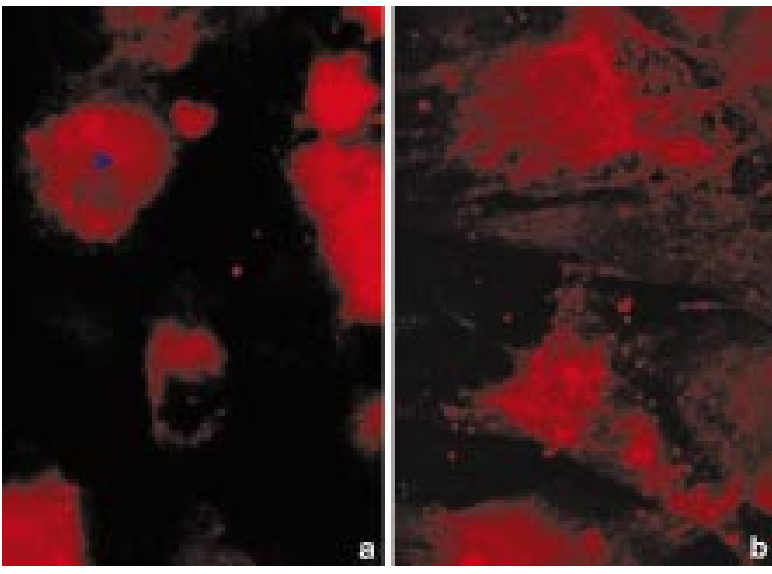

Fig. 9 - GM-CSF seems able to induce an increase in NHDF type I Collagen production: a, intracytoplasmatic immunopositivity in cells in basal condition after 7 days of culture; b, extracellular organization of type I Collagen after $80 \mathrm{ng} / \mathrm{ml}$ GM-CSF treatment at the same time. Magnification 1060x

inflammatory tissue involvement with cytokine production and a successive chronicization of pathology.

On the other hand, the true possibility to relate experimental results obtained with a stabilized cell line (also of human origin) to those obtained with cells of the same kind but from primary cultures is another important purpose of our work.

There is a frequent and perhaps sometimes inappropriate point of view that both types of cells have similar characteristics, simply on the basis that they are derived from the same tissue. In this case, we were surprised to find differences between these two in vitro cultured cell systems because we were expecting similar behavior. It is perhaps noteworthy that cell lines are undoubtedly useful but not perfectly analogous to cells obtained in conditions more similar to in vivo ones.

\section{ACKNOWLEDGEMENTS}

The Authors are grateful to Dr. Luca Vallefuoco for his constant assistance in cell culture and his experience in primary cultures assesment

\section{REFERENCES}

Bollberg S., Peltonen J., Uitto J., and Jmenez S.A.: Elevated expression of $\beta 1$ and $\beta 2$ integrins, intercellular adhesion mol- ecule 1 and endothelial leucocyte adhesion molecule 1 in the skin of patients with systemic sclerosis of recent onset. Arthritis Rheum. 35, 290-298, 1992

Bussolino F., Ziche M., Ming Wang J., Alessi D., Morbidelli L., Cremona O., Bosia A., Marchisio P.C., and Mantovani A.: In vitro and in vivo activation of endothelial cells by ColonyStimulating Factors. J. Clin. Invest. 87, 986-993, 1991.

Cooper S.M., Keyser A.J., Beaulieu A.D., Ruoslahti E., Nimni M.E., and Quismorio F.P.Jr.: Increase in fibronectin in the deep dermis of involved skin in progressive systemic sclerosis. Arthritis Rheum. 22, 983-987, 1979.

Cutolo, M.: Macrophages as effectors of the immunoendocrinologic interactions in autoimmune rheumatic diseases. Ann. N. Y. Acad. Sci. 876, 32-41, 1999.

Dedhar S., Gadboury L., Galloway P., and Eaves C.: Human Granulocyte-Macrophage Colony-Stimulating Factor is a growth factor active on a variety of cell types of nonhemopoietic origin. Proc. Natl. Acad. Sci USA 85, 9253-9261, 1988.

Denton C.P., Xu S., Black C.M., and Pearson J.D.: Scleroderma fibroblasts show increased responsiveness to endothelial cell-derived IL-1 and BFGF. J. Invest. Dermatol. 108, 269-274, 1997.

Fiocco, U., Rosada, M., Cozzi, L., Ortolani, C., De Silvestro, G., Ruffatti, A., Cozzi, E., Gallo, C., and Todesco, S.: Early phenotypic activation of circulating helper memory $\mathrm{T}$ cells in Scleroderma: Correlation with disease activity. Ann. Rheum. Dis. 52, 272-277, 1993.

Gruschwitz M.S., Homstein O.P., and Von Den Driesch P.: Correlation of the soluble adhesion molecules in the peripheral blood of Scleroderma patients with their in situ expression and with disease activity. Arthritis Reum. 38, 184-189, 1995.

Kaushansky K., Lin N., and Adamson J.W.: Interleukin-1 stimulates fibroblasts to synthesize Granulocyte-Macrophage and Granulocyte Colony-Stimulating Factors. J. Clin. Invest. 81, 92-99, 1998.

Kupper S.T.: Adhesion molecules in Scleroderma: Collagen binding integrins. Intern Rev. Immunol. 12, 217-225, 1995.

Lacour J.P., Vitetta A, Chiquet-Ehrismann R.,. Pisani A, and Ortonne J.P.: Increased expression of tenascin in the dermis in scleroderma. Brit. J. Dermatol. 127, 328-334, 1992.

Lang R.A., Cuthbertson R.A., Kelso A., Kannourakis G., Williamson D.J., Klintworth G.K., Gonda T.J., and Dunn A.R.: Transgenic mice expressing a hemopoietic growth factor gene (GM-CSF) develop accumulation of macrophages, blindness, and a fatal syndrome of tissue damage. Cell 51, 675-688, 1997.

Leroy C.E.: Connective tissue synthesis by Scleroderma skin fibroblasts in cell culture. J. Exp. Med. 135, 1351-1362, 1972.

Masi, A.T., Bijlsma, J.W., Chikanza, I.C., Pitzalis, C., and Cutolo, M.: Neuroendocrine, immunologic, and microvascular systems interactions in rheumatoid arthritis: physiopathogenetic and therapeutic perspectives. Semin. Arthritis Rheum. 29, 6581, 1999. 
McKeeham W.L., and Ham R.G.: Methods for reducing the serum requirement for growth in vitro of nontransformed diploid fibroblasts. Developmental Biology Standard 37, 9798, 1977.

Nakayama G.R., Caton M.C., Nova M.P., Parandoosh and Zahra: Asessment of the alamar blue assay for cellular growth and viability in vitro. Journal of Immunological Methods 204, 205-208, 1997.

Postiglione L., Montagnani S., Riccio A., Ladogana P., Salzano S., Vallefuoco L., and Rossi G.: Expression of GMCSF receptor and in vitro effects of GM-CSF on human fibroblasts. Life Science 63, 327-336, 1998.

Riccio A., De Caterina M., Natale D., Grimaldi E., Pronesti G., Montagnani S., and Postiglione L.: Serum levels of Granulocyte Macrophage Colony Stimulating Factor (GM-CSF) in a group of patients with Systemic Sclerosis. Int. J. Immunopathol. Pharmacol. 9, 9-12, 1996.

Roberts R., Gallagher G., Spooncer E., Aller T.D., Bloomfield F., and Dexter T.M.: Heparan sulfate bound growth factors: a mechanism for stromal cell mediated haemopoiesis. Nature 332, 276-278, 1988.
Sechler J.L., Corbett S.A., Wenk M.B., Schwarzbauer J.E.: Modulation of cell-extracellular matrix interactions. Ann.N.Y.Acad.Sci. 857, 143-154, 1998.

Varani J., Mitra R.S., Gibbs D., Phan S.H., Dixit V.M., Mitr R., Wang T., Siebert K.J., Nickoloff B.J., and Voorhees J.J.: All-trans retinoic acid stimulates growth and extracellular matrix production in growth-inhibited cultured human skin fibroblasts. Journal of Investigative 94, 717-723, 1990.

Vitale M, Illario M., Di Matola T., Casamassima A., Fenzi G.F., and Rossi G.: Integrin binding to immobilized collagen and fibronectin stimulates the proliferation of human thyroid cells in culture. Endocrinology 138, 1642-1648, 1997.

Vitale, M. Di Matola, T., Fenzi G., Illario, M.,and Rossi G.: Fibronectin is required to prevent thiroid cell apoptosis trough an integrin-mediated adhesion mechanism. J. of Clinical Endocrinology and Metabolism. 83, 3673-3680, 1998.

Xu W.D., Leroy E.C., and Smith E.A.: Fibronectin release by systemic sclerosis and normal dermal fibroblasts in response to TGF-beta. J. Rheumatol. 18, 241-246, 1991. 